\title{
$>$ Distopias e espaços sociais na produção artística contemporânea: espaços heterotópicos, heterocrônicos e heteróclitos
}

\author{
> Dystopias and social spaces in contemporary artistic production: \\ heterotopic, heterochronic and heterocyclic spaces
}

\section{por Paola Mayer Fabres}

Doutoranda em Artes Visuais, História, Crítica e Teoria da Arte, no Programa de Pós-graduação da Escola de Comunicação e Artes (ECA-USP). E-mail: paola.fabres@usp.br. ORCID: 0000-00031533-8728.

\section{Resumo}

$\mathrm{O}$ artigo objetiva discutir as relações que a produção artística tem estabelecido com as noções de espaço e de território na contemporaneidade, já que o surgimento de práticas voltadas a localidades específicas tem se tornado fenômeno global. Propõe-se um diálogo entre alguns exemplos dessas práticas imersivas com o conceito de "espaço heterotópico" de Foucault. Analisarei o modo como a arte tem agido frente ao desejo de construir novos espaços sociais e observarei a forma como a lógica utópica moderna tem sido revista: ao invés da busca por "espaços ideais", percebe-se o interesse em atuar junto a "espaços reais" e localizáveis. Assim, observarei estratégias distópicas da arte de problematizar territórios já existentes e seus processos políticos e culturais.

Palavras-chave: Arte contemporânea. Distopia. Espaço heterotópico. Michel Foucault.

\begin{abstract}
The article aims to discuss the relations that artistic production has established with the notions of space and territory in contemporary times, since the emergence of practices focused on specific localities has become a global phenomenon. A dialogue between some examples of these immersion practices with Foucault's concept of "heterotopic space" is proposed. I will analyze the way art has acted in the face of the desire to build new social spaces and look at the way modern utopian logic has been revised: instead of the search for "ideal spaces", the interest in working with localizable and "real spaces". Dystopian strategies of the art of problematizing existing territories and their political and cultural processes are observed.
\end{abstract}

Keywords: Contemporary art. Dystopia. Heterotopic space. Michel Foucault. 
No entanto, acredito que há - e em toda sociedade - utopias que têm um lugar preciso e real, um lugar que podemos situar no mapa; utopias que têm um tempo determinado, um tempo que podemos fixar e medir conforme o calendário de todos os dias. É bem provável que cada grupo humano, qualquer que seja, demarque, no espaço que ocupa, onde realmente vive, onde trabalha, lugares utópicos, e, no tempo em que se agita, momentos ucrônicos.

Michel Foucault, Heterotopias

A noção de utopia, tão cara às vanguardas históricas, vem sendo repensada no solo contemporâneo. O imaginário da modernidade, caracterizado pela crença depositada nos poderes de emancipação da arte, sofreu transformação ao longo do século XX. Ideias ligadas à evolução, ao funcionalismo e a luta por uma sociedade ideal começaram a ser colocadas em xeque na medida em que os encadeamentos históricos foram, aos poucos, evidenciando as falências relacionadas às ditas efetividades do projeto moderno. É nesse sentido que o esforço artístico em nome da utopia, barrado pelas resistências oferecidas pela própria realidade, afasta-se das tendências universalistas e teleológicas e inicia um processo de revisão sobre seu papel frente à melhoria da condição humana. Assim, qualquer crença na sua potência transformadora via programa universal começa a ser substituída, aos poucos, pela compreensão de que "efetuações

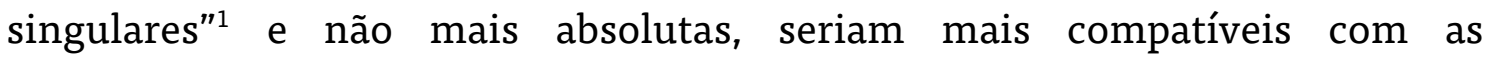
complexidades e particularidades das organizações sociais. Além do mais, ao invés do engajamento em nome da construção de espaços ideais inexistentes portanto irreais - observa-se no contexto contemporâneo o surgimento de

\footnotetext{
${ }^{1}$ Ricardo Fabbrini, 0 fim das Vanguardas: da modernidade à pós-modernidade, 2012, p. 31-47.
} 
práticas artísticas interessadas em observar e operar diretamente sobre espaços "reais"2 e localizáveis.

Essa tentativa de agir concretamente no território da cultura, material e afetivamente, tem estimulado práticas artísticas contrárias à ideia “já devidamente arquivada de utopia" ${ }^{3}$ mas que mobilizam intervenções sobre um outro tipo de espaço. Vale destacar que essa crescente proliferação de práticas artísticas tem apontado uma vontade de investigar localidades específicas e de ativar a significação de dinâmicas sociais, bem como as relações que essas dinâmicas estabelecem com seu entorno.

Arte "territorial", "littoral", "etnográfica", “colaborativa”, “participativa”, "comunitária", "relacional", "situacional" ou "socialmente engajada": o leque de nomenclaturas utilizado para comentar esses modos de produção é vasto e aponta para vertentes teóricas distintas. De todo modo, a propagação de termos que buscam definir essas práticas que se voltam aos binômios "arte-ativismo" e "estética-política" sugere o interesse que o sistema da arte tem demonstrado perante essas práticas, bem como um esforço por parte do campo literário específico em tentar compreendê-las. Não será tema do presente artigo tal problematização conceitual e terminológica, já que se entende que esse é um debate que pede fôlego argumentativo. Trata-se apenas de apontar a abundância de distintos modelos artísticos atentos ao contexto político de um determinado local. Afinal, a produção artística global de hoje indica cada vez mais uma

\footnotetext{
${ }^{2}$ Michel Foucault, Heterotopias, 2013, p. 14.

${ }^{3}$ Ricardo Fabbrini, Arte pós-utópica: heterotopia e comunidade, 2018, p. 108.
} 
aproximação entre artistas e contextos comunitários, geográficos, sócioculturais e suas particularidades.

O interesse direcionado à ideia de território vem estimulando projetos artísticos que criam "mecanismos que permitem articular processos de modificação do estado de coisas locais" e de "produção de ficções, ativações, intervenções de maneira que ambos os aspectos se reforcem mutuamente" ${ }^{14}$. Essas produções aliam-se a impulsos ativistas e substituem a ideia tradicional de experiência estética por lógicas processuais irregulares e imprecisas. Além do mais, conforme comenta Grant Kester, teórico focado nas relações entre a arte e o campo social, ao desmantelar qualquer noção moderna de autonomia e evidenciar uma porosidade interdisciplinar, elas assinalam com maior vigor uma permeabilidade entre a arte e outras zonas de produção simbólica (como urbanismo, ativismo ambiental, antropologia, filosofia, gestão política, educação, direito etc.), exigindo, assim, uma atenção sobre as correspondências que se dão entre a arte e as outras esferas da cultura. ${ }^{5}$ Ao longo desses processos, tais projetos buscam também compreender a interação complexa entre o discursivo e o político que estrutura qualquer local.

Desse modo, proponho aqui que aproximemos tal tipo de prática artística aquela que surge de um determinado lugar, que pede uma compreensão aguda sobre sua singularidade e seus modos de operação, que emerge das intersubjetividades de uma determinada comunidade e que debate as tensões

\footnotetext{
4 “la invención de mecanismos que permitieran articular procesos de modificación de estados de cosas locales [...] y de producción de ficciones, fabulaciones e imágenes, de manera que ambos aspectos se reforzaran mutuamente". Reinaldo Laddaga, Estética de la Emergencia: la formación de otra cultura de las artes, 2006, p. 08, tradução nossa.

${ }^{5}$ Grant Kester, “About FIELD”, 2019.
} 
políticas que estão em jogo nesse mesmo local - com o conceito de heterotopia de Foucault, elaborado especialmente ao longo de duas conferências por ele proferidas, no ano de 1966: ${ }^{6}$

Pois bem, sonho com uma ciência - digo mesmo uma ciência - que teria por objeto esses espaços diferentes, esses outros lugares, essas contestações míticas e reais do espaço em que vivemos. Essa ciência estudaria não as utopias, pois é preciso reservar esse nome para o que verdadeiramente não tem lugar algum, mas as heterotopias, espaços absolutamente outros; e, forçosamente, a ciência em questão, se chamaria, se chamará, já se chama "heterotopologia"7.

De acordo com Michel Foucault, há uma diversidade explícita, viva e latente daquilo tudo que poderia ser entendido como "espaços heterotópicos". Tais locais, espalhados mundo afora, podem ser reconhecidos a partir do termo heterotopia, conceito de geografia humana que denota "espaços intervalares", espaços de resistência isolados das condições normativas e que contestam de forma simbólica, mítica e real nossas estruturas sociais. ${ }^{8}$ Diferenciam-se, portanto, do modelo normativo de espaço. Museus, hospícios, mausoléus, circunstâncias ritualísticas, esses e tantos outros locais vêm sendo mapeados por Foucault ao condensar em si mesmos lógicas de comportamento e temporalidades distintas daquelas habituais, bem como por representarem modelos de dissidência. São espaços que atuam de modo não hegemônico, que possuem múltiplas camadas de significação e que disparam, eles mesmos,

\footnotetext{
${ }^{6}$ Daniel Defert, "Heterotopias: Tribulações de um conceito entre Veneza, Berlim e Los Angeles", 2013, p. 33.

${ }^{7}$ Michel Foucault, Op. Cit., 2013, p. 35.

${ }^{8}$ Ibidem, p. 20.
} 
paradoxos e discrepâncias com relação ao seu entorno: “As heterotopias, por sua vez, são 'contraposicionamentos em lugares reais', 'lugares efetivos', - ou seja, 'lugares que, em aparente paradoxo, estão fora de todos os lugares, embora sejam, efetivamente localizáveis"'?

Para Ricardo Fabbrini, é importante salientar que a intenção de Michel Foucault ao longo de seus pronunciamentos não era prescrever ou categorizar, empiricamente, lugares heterotópicos em sua exaustão, mas ajudar a figurá-los, a imaginar "ambiências heterotópicas" que evidenciassem uma "existência de espaços singulares" que encontramos no interior dos "espaços sociais já existentes"10. Reconhecê-los e compreendê-los, mais do que mapeá-los em sua totalidade. No entanto, ainda que a ampla tipologia de tais espaços observados e debatidos por Foucault tem sido há muito tempo produto de todo e qualquer grupo humano, bem como de toda e qualquer circunstância histórica, o campo da arte também se aproxima desses espaços e opera junto a eles. Assim, produções artísticas e intelectuais passam a se dedicar, em especial desde a década de 1960, a um exercício de interpretação qualitativa dos espaços outros. ${ }^{11}$

Partindo dessas considerações, e entendendo a emergência dessas práticas sociais contemporâneas como um fenômeno abrangente, assinala-se a importância de observar a insurgência do interesse pela questão da localidade por parte da produção artística e de analisar as relações que ela vem estabelecendo com o território e seus coeficientes políticos. Em diálogo com Foucault, mais do que propor uma aproximação às variadas formas de

\footnotetext{
${ }^{9}$ Michel Foucault, Ditos e escritos III: Estética: literatura e pintura, música e cinema, 2001, p. 415.

${ }^{10}$ Ricardo Fabbrini, Op. Cit., 2018, p. 108.

${ }^{11}$ Ibidem, p. 109.
} 
heterotopias concebidas pelas sociedades ao longo da história, o presente artigo busca observar a organização de heterotopias pela produção da arte contemporânea e analisar o modo como algumas delas tem disparado reflexões sobre a esfera social e sobre sua vontade de interferência na esfera pública. Para a elaboração desse debate, partirei de dois trabalhos artísticos que me parecem pertinentes para se pensar o conceito foucaultiano em pauta.

\section{Na Argentina, noroeste da província de Buenos Aires}

Irene Serra, artista argentina, foi participante da residência Comunitária, programa voltado à articulação entre arte e processos sociais. Durante a residência, permaneceu no povoado de Triunvirato, pequeno município situado ao noroeste da Província de Buenos Aires. A região é rodeada por pequenas cidades e vilarejos que vêm enfrentando processos bastante drásticos de decrescimento demográfico. As localidades, anteriormente acessadas e abastecidas a partir da antiga linha férrea, sistema de transporte que permitia acesso aos vilarejos, hoje sofrem com a ausência do trem. Triunvirato, que chegou a ter mais de 2.000 habitantes em sua organização, conta atualmente com cerca de 100 moradores.

Nesse sentido, o povoado se esforça atualmente para garantir sua própria existência. Destituído de hospitais, supermercados, padres, missas, escolas de nível médio ou de qualquer tipo de ensino técnico e superior, o pequeno distrito deve organizar-se de forma quase autônoma. A distribuição de guarnecimentos e utilidades ocorria, com sorte, uma vez por semana por um pequeno caminhão que vinha da cidade, o que levou a comunidade a se dedicar a agricultura de 
subsistência. Era curioso perceber o amplo uso de enxadas, foices e arados nos terrenos das próprias casas e dos espaços baldios, enquanto toda área que rodeava o distrito exibia uma estrutura impactante de maquinários e tratores que otimizavam o plantio de trigo. Havia algum descompasso temporal e tecnológico entre a pequena área urbana, aparentemente estacionada no passado, e a grandeza rural e agrícola atualizada que circundava aquele distrito. Irene Serra se interessou nos fatores simbólicos e culturais implicados nessa fronteira.

A artista observou com atenção a presença que a cultura tradicional exercia nos hábitos locais. As milongas, cumbias e bachatas soavam nas rádios, o mate circulava constantemente e os trajes gauchos eram utilizados no dia a dia. Percebeu a cinta de tecelagem que os homens usavam na indumentária gaúcha, a grande maioria apresentava as mesmas tramas decorativas. Os desenhos dessas cintas remetiam aos grafismos geométricos herdados pelos povos nativos, já há tanto tempo dizimados, e acionavam um passado ancestral que ainda perdurava na vestimenta da população rural. Até onde se sabe, cada tipo de grafismo remete a tribos e a agrupamentos familiares específicos. O nome dado a essas cintas foi Guarda Pampa. Foi da convergência da estética dessa indumentária específica com a paisagem social e geográfica de Triunvirato que nasceu o trabalho elaborado por Irene Serra. 

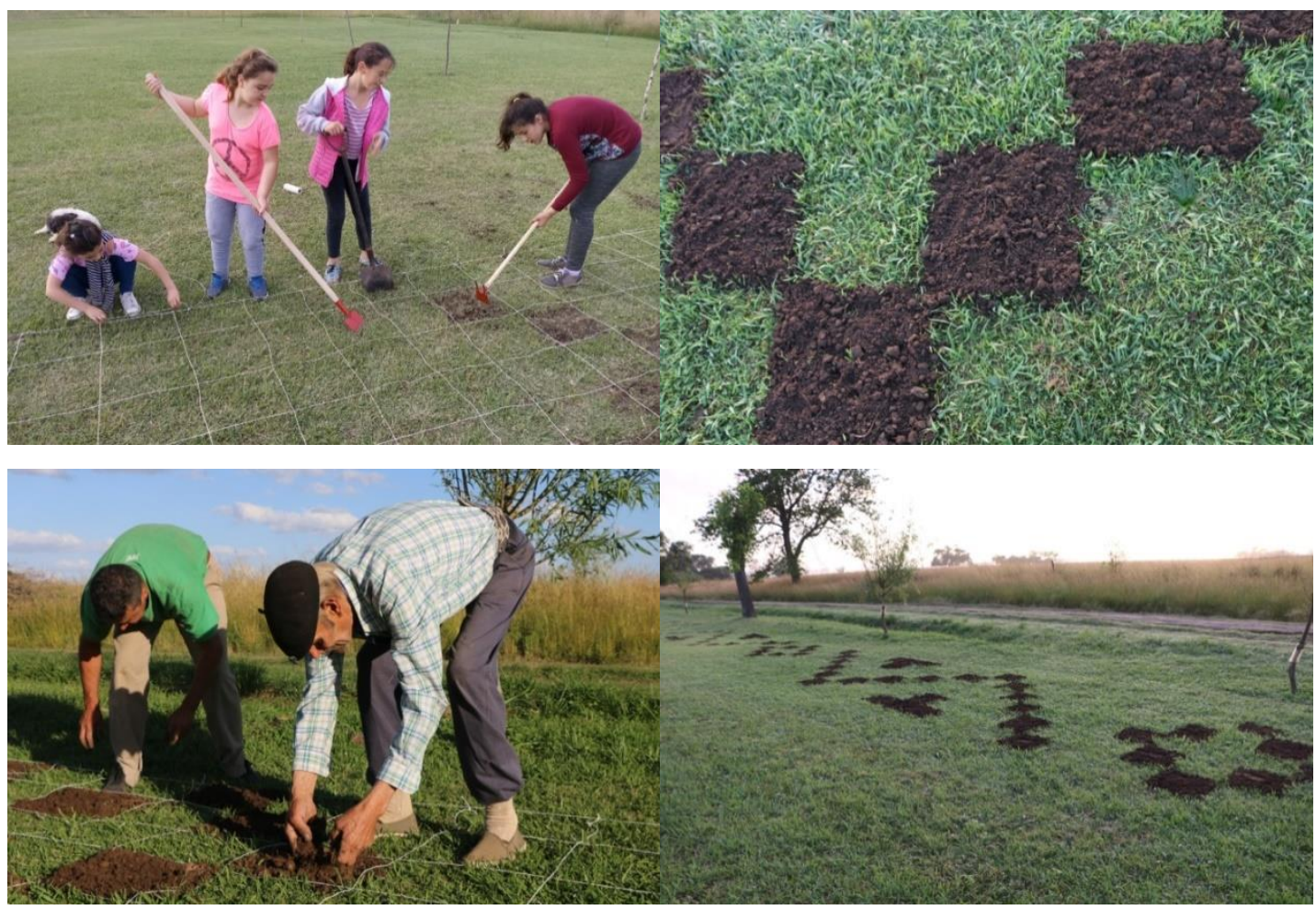

Figura 1

Irene Serra, Guarda Pampa! Comunitária, Triunvirato, Argentina, 2018. (Fonte: Irene Serra)

A artista dirigiu-se ao limite que circundava o vilarejo em meio ao pampa: exatamente no encontro entre aquilo que era ainda cidade e toda a extensão do campo que a rodeava. Bem junto à estrada que dava acesso ao povoado, de um lado encontravam-se o clube, a igreja e a praça central de Triunvirato, do outro, a imensidão rural. Se “a história dos poderes é afinal uma história dos espaços, através dos quais o poder se mostra"12, essa fronteira que delimitava a atividade monocultora latifundiária e o povoado em extinção sublinhava precisamente os embates de poder que emergiam daquele espaço. Nessa divisa entre o pequeno

${ }^{12}$ Daniel Defert, Op. Cit., 2013, p. 48. 
município e os tantos hectares de plantação de trigo, Irene Serra se dedica a propor uma intervenção. Usa a própria enxada - ferramental habitual de Triunvirato - para deixar uma marca sobre o solo, uma sinalização, um pedido de atenção gravado na própria terra. Afinal, aquele choque entre o "urbano" e o "não-urbano", entre o dentro e o fora, entre um processo de progresso interrompido e entre um desenvolvimentismo produtivo desenfreado, muito nos diz sobre aquele território e sobre tantos outros ao seu redor.

\begin{abstract}
A palavra guarda era utilizada para se referir à pessoa que controlava os boletos dos passageiros nos trens. A bainha da foice de poda é chamada de guarda, assim como o cabo de uma arma branca. No jogo de cartas, guarda é a carta baixa que serve para reservar a melhor qualidade. Guarda! é uma expressão lunfarda, usada para se referir à miscigenação. É também coloquialmente usada como uma chamada de alerta, calma lá! ou como um grito de aviso para ficar em estado de alerta. Assim, em frente aos pampas verdes e férteis que desaparecem após as formas de cultivo intensivo e após os processos de despovoamento causado pelos jovens que migram, Guarda Pampa! aparece como um grito. Aponta um lugar e assinala uma urgente preservação daquele modo de organização camponês, baseado em relacionamentos espontâneos e acordos tácitos. [Depoimento da artista, após o encerramento do programa de residência $]^{13}$.
\end{abstract}

Ao trazer o grafismo das guardas que simbolizavam o passado histórico daquela comunidade - seus costumes, sua cultura e seu modo de produção - a artista estabelecia um contraponto preciso entre a dinâmica do pequeno produtor e a produção monocultora que assolava as planícies da região. $\mathrm{O}$ trabalho proposto por Serra justapôs, "em um lugar real", diferentes "espaços [...] incompatíveis"14. Concebida por ela e pelos moradores do vilarejo, aquela grande

\footnotetext{
${ }^{13}$ Irene Serra, "Entrevista com Irene Serra", 2019, n. p.

${ }^{14}$ Michel Foucault, Op. Cit., 2013, p. 24.
} 
cinta de padrões geométricos atuava quase como um muro simbólico protetor assentado na divisa entre a organização urbana e a vastidão dos campos da produção rural.

\section{No Sul do Brasil, no município de Arroio dos Ratos (Rio Grande do Sul)}

Maria Helena Bernardes, artista brasileira, passou meses entre Porto Alegre, local onde habitava, e o pequeno município de Arroio dos Ratos. Arroio dos Ratos havia um dia sido a primeira mina de carvão da América Latina, área pioneira da mineração: "Até a princesa Isabel havia vindo de lá [...] para inauguração. Viajou toda essa distância" - disse um fazendeiro local, contemplando as ruínas restantes ${ }^{15}$. Contudo, hoje apresenta um dos menores índices demográficos da região carbonífera e uma vulnerabilidade na sua condição socioeconômica - algo diferente da realidade encontrada nos tempos áureos da extração do carvão mineral. Aquela região - assim como povoados do interior da argentina - já assistia seu próprio declínio produtivo.

Ao chegar na pequena cidade, Maria Helena Bernardes, imersa na paisagem de planícies e coxilhas, localiza um terreno um pouco diferente: era um grande campo inócuo entre outros ainda férteis. Este especificamente havia sido por muito tempo área de depósito de um tipo de carvão considerado imprestável para a queima na Usina. Hoje, era apenas uma vaga em um campo de rejeitos:

O local era uma espécie de campo mineral, de solo batido e granulado, limpo como se fosse pedra. Aquele foi o primeiro dado que me intrigou, o

\footnotetext{
${ }^{15}$ Maria Helena Bernardes, Vaga em campo de Rejeito, 2003, p. 12.
} 
chão pedregoso, sem nada verde e que, visto de longe, parecia coberto de brita. [...] $\mathrm{O}$ campo à nossa frente foi uma área de minas no passado. Uma rede de túneis vazava o subsolo situado abaixo de nossos pés ${ }^{16}$.

Ao observar esse campo improdutivo, volta-se a indagar sobre o sentido de funcionalidade que normalmente aplicamos a nossas experiências e expectativas habituais. Esperamos resultados efetivos em tudo aquilo que vemos ou fazemos. Uma terra um dia ativa, sem qualquer serventia, acionava o sentido do fracasso. O campo extenso, aparentemente imprestável não combinava com os anseios desenvolvimentistas que caracterizam os tempos atuais, contrapondo-se às lógicas dos lucros e rendimentos. Aquilo tudo lembrou a artista do papel que as mineradoras de carvão tiveram no crescimento das cidades, seus desequilíbrios e assimetrias sociais. Em frente à terra infértil, ciente que todos aqueles campos à época da extração deram corpo à estrutura urbana circundante, Bernardes se dirigiu à cidade. Queria observar se seria possível encontrar na estrutura do município algum local parecido com aquele - algum local que denotasse sua derrota: uma vaga, um vão, um espaço infecundo na urbe de Arroio dos Ratos.

Pela cidade, buscou terrenos que pudessem se equivaler ao campo inútil. O que seria um espaço inútil dentro de um pequeno município? Vagas de estacionamento? Terrenos baldios? Calçadas de pedestres? Todos esses traziam consigo algum tipo de utilidade, diferente daqueles hectares mapeados pela artista. Após alguns meses em contato com a cidade, avista uma pequena área, cimentada, junto à rodoviária. Algo entre uma laje em despropósito e uma praça sem qualquer sinal de praça jazia, sem jeito, entre a estação de ônibus e a Câmera

\footnotetext{
${ }^{16}$ Ibidem.
} 
dos Vereadores. Era um pedaço de terreno triangular que para nada servia. Estaria mesmo vago? Descobre que antigamente servia de entrada para que caminhões descarregassem carne, na época em que a rodoviária era um açougue. Depois, surgiram planos de fazer ali uma peixaria. Para a artista, aquilo parecia uma história de outro lugar. Aquele espaço "era muito pequeno para caminhões e abafado demais para peixes"17. Enquanto nada disso acontecia, não era nada e não prestava para ninguém.

Observou as similaridades entre esse espaço vazio e aquela terra, infértil, rural. Com o intuito de apreender aquele canto e de estudar aquele espaço, mediu-o cautelosamente. Anotou diagonais, perímetros, áreas e inclinações. Compreendeu aquela superfície da melhor forma que pode e a replicou sobre o campo de rejeito. Apreendeu aquele vazio. Talvez se ele se soltasse do seu confinamento urbano, se desassociasse das construções que o ladeavam, talvez se ele se emancipasse poderia, então, ser percebido de outra forma. Maria Helena Bernardes já sabia onde o levaria. Já sabia qual era o chão, livre da amarra do dever racional, que o sustentaria.

Transplantou, assim, aquele plano intersticial. Despejou sobre o terreno rural toneladas de cimento, construindo uma área sobre a outra. Levou a vaga da cidade ao campo, acomodando-a gentilmente sobre a paisagem natural. Espelham-se um ao outro, mas refletem também indícios de suas divergências. Era um grande monumento ao vazio, um bloco cimentado rodeado pela lavoura ainda ativa, uma calçada ensimesmada que não levava a destino algum. Além do esforço em buscar encontrar o que é invisível, em apreender o que escapa à forma,

\footnotetext{
${ }^{17}$ Maria Helena Bernardes, Op. Cit., 2003, p. 26.
} 
em capturar o que se nega a ser retido, existia naquela ação um gesto de doçura que parecia tentar salvar o que sofre rejeição e dar valor ao que nem sequer é avistado. Aceita-se, assim, um universo de existências e de coisas sem valores aparentes. Repensa-se, assim, a ideia de valor ao criar-se um "campo fecundo" a partir do "pensamento vago"18. Uma pausa aos anseios do progresso e da expansão. Restou ali uma sinalização simbólica dos malogros da extração, uma ode às inutilidades, um elogio às coisas rejeitadas:

Em Vaga em campo de rejeito, a ocorrência simultânea de situações antagônicos nos revela que, através da ligação entre partes em que não há consenso, podemos alcançar uma liberdade de pensamento baseada na mobilidade da experiência. Condição esta que pode nos levar para além do nosso conhecimento e de nossas tentativas e expectativas individuais. Não se trata, entretanto, de defender qualquer necessidade, ou vontade, de atacar a objetividade, o encadeamento lógico de ideias, mas apostar na possibilidade de desdobramento de novas potencialidades intelectuais. $\mathrm{O}$ que defendo aqui, e o que o trabalho de Maria Helena Bernardes talvez demonstre, é que no campo de rejeito das situações cotidianas dos pensamentos exatos e das autocertezas estabelecidas, talvez nos coloquemos em condições de desenvolver outras maneiras, modos diferentes de nos relacionarmos com a vida e, quem sabe, com a arte. Podemos, a partir destas reflexões, pensar que possuir uma personalidade espiritual e desenvolver um raciocínio que não seja necessariamente exato, talvez possa se revelar como uma possibilidade de entendermos as coisas de maneiras distintas, de acreditarmos nas novas orientações que podem chegar. Sabe-se lá quantas coisas novas enxergaríamos, quantas coisas diferentes se fundamentariam intimamente se desenvolvêssemos a capacidade, por alguns que seja, de deixarmo-nos persuadir contra nossas próprias crenças, de colocarmos à parte determinados elementos, tidos como absolutos, da nossa consciência e tentar transformá-los, ampliá-los e uma nova e desarticulada convicção. [Citando Robert Smithson] Somente quanto a arte é fragmentada, descontínua e incompleta, podemos entender algo sobre a perenidade vaga que exclui objetos e determina significados" ${ }^{19}$.

\footnotetext{
${ }^{18}$ André Severo apud Maria Helena Bernardes, Op. Cit., 2003, p. 74.

${ }^{19}$ Ibidem, p. 87-88.
} 

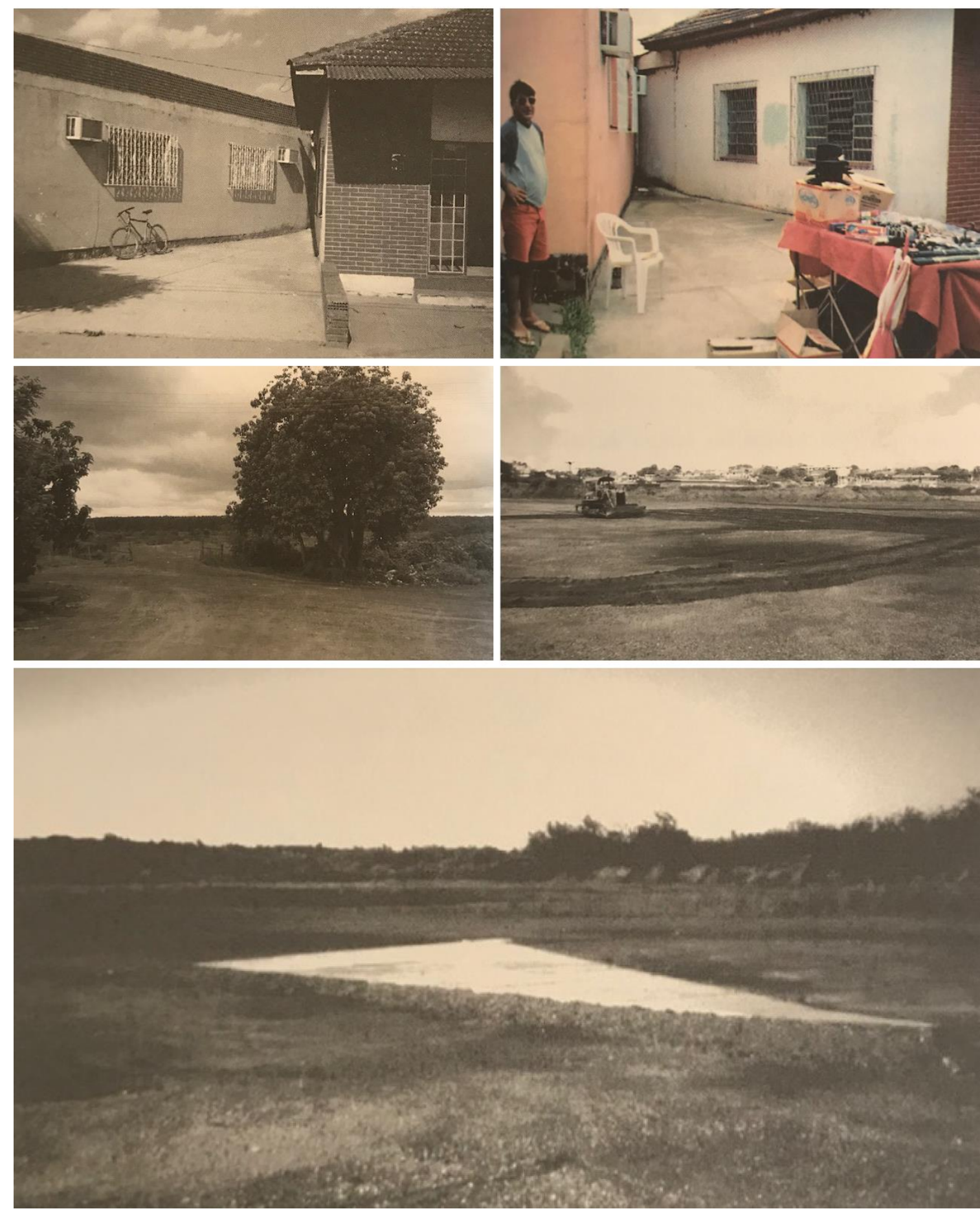

Figura 2

Maria Helena Bernardes, Vaga em Campo de Rejeito, Arroio dos Ratos, RS-Brasil, 2001-2003.

(Fonte: Maria Helena Bernardes) 


\section{Considerações finais}

Sabemos que essas proposições que se constituem a partir de uma imersão imediata no território da cultura têm ganhado notoriedade nos últimos tempos. Para Reinaldo Laddaga, os anos 1990 marcam um período de proliferação de projetos que começam a assinalar uma reação ao esgotamento perante o paradigma moderno (e à insuficiência dessa classe de respostas que identificávamos como pós-modernas). Assim, artistas começam a abandonar grande parte dos gestos, das formas e das heranças herdadas pelo regime da arte, dando margem a modos particulares de se mapear, observar e especializar os problemas, de incorporá-los e devolvê-los ao mundo como reflexões. Reinaldo Laddaga observa esse tipo de práxis artística a partir do conceito de "estética da emergência"20: aquela que emerge de contextos particulares corroborando um vínculo intrínseco com a paisagem social. Para ele, a noção de emergência está diretamente atrelada a um momento súbito ou inesperado. De caráter repentino, a "emergência" torna-se uma ocasião intervalar, de suspensão. Segundo o autor, ao longo da história, poderíamos pensa-la como um instante de desconforto que, em geral, afronta a continuidade do senso social comum. Já não se trata mais de um pensamento criativo que propõe uma visão sólida de mundo, pelo contrário, nesses casos, a obra de arte torna-se um espaço de confluência de sujeitos em transformação, em curso de invenção, e em direção a uma comunidade possível.

Assim opera a emergência: na articulação das conversações e na distribuição dos suportes e dos espaços, para que aquilo que se pode "pensar" possa também ser "feito". Uma "desinvenção da modernidade",

20 "Estética de la Emergencia", título do livro de Reinaldo Laddaga, Op. Cit., 2006, p. 81, tradução nossa. 
como quer Bruno Latour, ou uma "ampliação dos âmbitos de deliberação", como quer o coletivo de escrita Wu Ming, ou a "articulação entre uma grande intensidade de participação e a manutenção da integração entre as partes", como quer o projeto Linux. Como na escritura de Saer e Sebald (todos eles exemplos de Laddaga), a subjetividade da arte é múltipla e se dá na errância, na construção de personagens (eu, ele, você) imersos em um tempo não da progressão, mas da sobreposição e da interação ${ }^{21}$.

Mas como entender a perspectiva (dis)utópica desses raciocínios artísticos? Como compreender a relação que eles buscam estabelecer com territórios específicos e com as suas urgências? Pode-se dizer que ambos trabalhos aqui citados problematizam as emergências daquelas localidades, aguçam um olhar sobre suas dinâmicas e se esforçam em assinalar alguns de seus espaços simbólicos latentes. Ao repensar tais espacialidades e ao reconfigurá-las via linguagem artística contemporânea, instituem, portanto, novas figuras de tempo e de espaço ao estimular contatos entre territórios antagônicos e temporalidades discrepantes.

Tais regiões vêm sofrendo as consequências do êxodo rural, os efeitos da busca desenfreada pelo crescimento econômico, as sequelas dos impulsos desenvolvimentistas do projeto moderno e as violentas decorrências que os antigos e atuais modos da exploração de recursos naturais ainda ocasionam. Ao sublinhar embates entre a produtividade e a inoperância, entre um passado desenvolvimentista e um presente atingido por essas explorações, os trabalhos de Irene Serra e de Maria Helena Bernardes sinalizam o enfrentamento de paisagens distintas e jogam luz sob a "incongruência dos conteúdos" ${ }^{22}$ que designam as arquiteturas desses locais. Heterotópicos e heterocrônicos,

\footnotetext{
${ }^{21}$ Suplemento Pernambuco, As emergências que podem nos revelar, 2012, n. p.

${ }^{22}$ Daniel Defert, Op. Cit., 2013, p. 49.
} 
estabelecem um arco reflexivo e imagético entre presente e passado: a realidade de um passado ainda vigente e as novas forças que se afirmam enquanto futuro.

Além do mais, tais exemplos citados dão-se fora dos limites das grandes cidades, estimulando, assim, a reflexão sobre o impacto de um mundo cada vez mais urbanizado nas áreas não urbanas. Essas fronteiras físicas e simbólicas têm atuado diretamente na organização de pequenos municípios e, muitas vezes, têm contribuído com seus desmantelamentos, uma vez que a mecanização da produção rural tem afetado os sistemas de trabalho e serviço das cidades e distritos circundantes. Afinal de contas, junto com a reconfiguração da relação entre espaços urbanos e rurais - fator consequente dos fluxos globais -, insurgem sintomas diretos nas esferas de energia, de alimento, de capital, de políticas públicas e das próprias pessoas. Os novos modos de produção e extração têm tido direta interferência nesses territórios, anunciando cada vez mais situações de abandono e obsolescência. Tais contrastes e fronteiras temporais, culturais e econômicas constituem também parte da complexidade que essas regiões nos apresentam:

Nas heterotopias, [...] teríamos, segundo Foucault, uma justaposição tanto de espaços, quanto de tempos. A heterotopia, um lugar singular espaçotemporal, "teria o poder de justapor em um só lugar real vários espaços, vários posicionamentos que são em si próprios incompatíveis". Seu poder de resistência ou de contraposicionamento resultaria, portanto, da dimensão compósita, paratática, de justaposição de elementos espaciais heteróclitos [...]. As heterotopias no tocante a temporalidade, seriam acrescenta ainda Foucault (2001, p. 419) - "recortes singulares do tempo", o que o autor denomina, "por pura simetria", "heterocronias", que 
operariam uma "ruptura absoluta com o tempo tradicional", em um $\operatorname{lugar}^{23}$.

Irene Serra sabia que a manutenção daquele trabalho exigiria um cuidado bastante constante por parte das pessoas que habitavam o local. Sabia que o tempo faria a grama crescer e que apenas a dedicação diária poderia garantir a permanência daquela sinalização. Sabia que a passagem do tempo, com rapidez e facilidade, apagaria o que havia sido gravado ali. O gesto da artista, impresso no solo enquanto o tempo lhe permitisse, condensou em si os próprios riscos que o contexto ao seu redor lhe apresentava: as urgências da produção e da exploração global capitalista que apagam povoados e memórias culturais. Tal efemeridade, tal condição tão natural e ao mesmo tempo tão fugaz, colocou o trabalho de Serra na chave das heterotopias temporais - não perpétua como os museus ou cemitérios, mas passageira bem como as festas, as feiras ou os rituais cerimoniosos que indicam a brevidade de sua própria existência.

Para Foucault, em síntese, as heterotopias são espaços de resistência: lugares que a sociedade dispõe em suas margens, nas paragens vazias que as rodeiam aos indivíduos cujo comportamento é desviante relativamente à média ou à norma exigida. Elas pressupõem um sistema de abertura e fechamento que as isola do espaço circundante, ou melhor, que as isola parcialmente [...] porque são espaços intervalares, de mediação, limiares onde se fica por certo tempo, entre o dentro e o fora ${ }^{24}$.

Ao aproximar essas produções do pensamento de Michel Foucault, vale comentar que esses trabalhos operaram em uma sincronia e diacronia específica.

\footnotetext{
${ }^{23}$ Ricardo Fabbrini, Arte pós-utópica: heterotopia e comunidade, 2018, p. 114.

${ }^{24}$ Ibidem, p. 115.
} 
Por suas formas, suas funções e suas rupturas, constituem-se enquanto jogos de oposição. É nesse sentido que gostaria de sugerir que além de heterotópicos e heterocrônicos, são também linguagens heteróclitas, já que amalgamaram elementos distintos e incompatíveis em um só local. Afinal, "a heterotopia arruína não somente a sintaxe das frases, como também aquela, menos manifesta, que autoriza manter juntas as palavras e as coisas" 25 . Os trabalhos Vaga em campo de rejeito e Guarda Pampa! causavam surpresa e incompreensão por parte da comunidade local que se esforçava em tentar encontrar alguma finalidade ou serventia em grafismos desenhados sobre a grama ou em concretos cimentados triangulares "aleatoriamente" disposto pelo campo infértil, em meio ao nada.

Mas é interessante buscar perceber os efeitos dessas incompreensões imediatas e dessa não objetividade. O estranhamento provocado pelas singularidades estéticas e (não) funcionais desses trabalhos fez deles incognoscíveis perante seu entorno. E "toda ação não-funcional" encontra atualmente, no intelecto coletivo, motivos para ser rejeitada ou condenada, “assim como seus opostos fundamentados encontram motivos para serem defendidos e exaltados"26. Portanto, correm o risco de se tornarem prescindíveis.

É certo que, diferentemente do mecanismo reformista, as intervenções de Serra e Bernardes não constroem espaços ideais. Não solucionam problemáticas latentes, nem suavizam a agonia do padecimento daquelas localidades. Tampouco buscam projetar respostas para que se evite futuramente o

\footnotetext{
${ }^{25}$ Daniel Defert, Op. Cit., 2013, p. 36.

${ }^{26}$ André Severo apud Maria Helena Bernardes, Op. Cit., 2003, p. 74.
} 
surgimento de novas localidades desprestigiadas, dispensáveis e improfícuas. Distópicas e excêntricas, apenas delimitam e circundam emergências atuais, sem movimento de transformação. E, enquanto isso, garante-se a elaboração e a apresentação de sistemas de ruptura por meio de práticas que contribuem ao sublinhar e identificar espaços particulares: espaços que condensam em si lógicas da vida e da sociabilidade; bem como lógicas de abandono e padecimento.

\begin{abstract}
Esses contraespaços, porém, são interpenetrados por todos os outros [...], há reverberação dos espaços uns nos outros, e contudo, descontinuidades e rupturas. Há, enfim, como que um eterno retorno desses rituais espaçotemporais e, se não universalização das mesmas formas, ao menos uma universalidade de sua existência. Eles são apreendidos em uma sincronia e diacronia específicas que fazem deles um sistema significante. Não refletem a estrutura social nem a da produção, não são um sistema sócio histórico nem uma ideologia, mas rupturas da vida ordinária, imaginários, representações polifônicas da vida, da morte, do amor, de Éros e Tánatos ${ }^{27}$.
\end{abstract}

Sabemos que, para além dos exemplos citados, encontram-se práticas que ainda creem na arte como ferramenta objetiva e direta de reparação da melhoria humana. Propostas que apostam na afetação imediata e que buscam agir na interferência de qualquer problema diagnosticado. Micro utópicas, usam da linguagem da arte para reorganizar um determinado território. Por outro lado, em tais exemplos citados, a gritante disfunção que caracteriza esses trabalhos nos evidencia linguagens que evitam o reparo enquanto intuito, mas que apostam na dissidência, no estranhamento e no pensamento não linear como uma alternativa para gerar a reflexão. Distópicos, não apostam em transformar um local existente em nome do seu restauro e desenvolvimento, tampouco em

\footnotetext{
${ }^{27}$ Daniel Defert, Op. Cit., 2013, p. 38.
} 
reerguer novos modelos espaciais e novas propostas de organização cívica, econômica, urbana ou cultural. Repensam, por outro lado, como viemos nos organizando socialmente ao longo do tempo, observando ainda quais efeitos têm surtido a partir desses processos. Apostam, dessa forma, em tencionar sujeitos de um determinado entorno; em construir novos olhares e em possibilitar a elaboração de novos entendimentos.

\section{Referências}

BERNARDES, Maria Helena. Vaga em campo de rejeito. São Paulo: Escrituras Editora, 2003.

DEFERT, Daniel. "Heterotopias": Tribulações de um conceito entre Veneza, Berlim e Los Angeles. In: FOUCAULT, Michel. O corpo utópico, as heterotopias. São Paulo: Edições n-1, 2013. p. 33-55.

FABBRINI, Ricardo. O fim das Vanguardas: da modernidade à pósmodernidade. Seminário Música Ciência Tecnologia, [s. l.], n. 4, p. 31-47, 2012.

FABBRINI, Ricardo. Arte pós-utópica: heterotopia e comunidade. In: VACCARI, Ulisses Razzante (Org.). Arte \& Estética. Marília: Oficina Universitária São Paulo; Cultura Acadêmica FFC- UNESP, 2018. p. 105-128.

FOUCAULT, Michel. Heterotopias. In: FOUCAULT, Michel. O corpo utópico, as heterotopias. São Paulo: Edições n-1, 2013. p. 19-30.

FOUCAULT, Michel. Ditos e escritos III: Estética: literatura e pintura, música e cinema. Rio de Janeiro: Forense Universitária, 2001. 
KESTER, Grant. About FIELD. Field: A Journal of Socially-Engaged Art Criticism, [s. d.]. Disponível em: http://field-journal.com/about. Acesso em: mar. 2019.

LADDAGA, Reinaldo. Estética de la Emergencia: la formación de otra cultura de las artes. Buenos Aires: Adriana Hidalgo, 2006.

SERRA, Irene. Entrevista com Irene Serra. Comunitaria Argentina - Residência da arte contemporânea e dos processos sociais, [s. d.]. Disponível em: https://residenciacomunitaria.com.ar. Acesso em: nov. 2019.

SUPLEMENTO Pernambuco - Suplemento Cultural do Diário Oficial do Estado. As emergências que podem nos revelar. Resenha. n. 72, 2012. Disponível em: http://www.suplementopernambuco.com.br/edi\%C3\%A7\%C3\%B5esanteriores/72-resenha/880-as-emergencias-que-podem-nos-revelar.html. Acesso em: set. 2018.

\section{Referência para citação deste artigo}

FABRES, Paola Mayer. Distopias e espaços sociais na produção artística contemporânea: espaços heterotópicos, heterocrônicos e heteróclitos. Revista PHILIA | Filosofia, Literatura \& Arte, Porto Alegre, volume 2, número 1, p. 462 - 484, junho de 2020. 